\title{
Protests at Indian solar observatory refit
}

[NEW DELHI] The Indian Institute of Astrophysics (IIAP) in Bangalore has triggered a fierce controversy with a plan to convert part of the 100-year-old Kodaikanal Solar Observatory in southern India into a modern auditorium that will host an international scientific meeting.

The meeting, supported by the International Astronomical Union, will be held in December as part of the centenary celebrations for the observatory, which sits on the Palani Hills. Its six-inch telescope has been monitoring the Sun since 1899.

It was at Kodaikanal, 90 years ago, that John Evershed discovered the phenomenon of radial motion in sunspots - the Evershed effect has only recently been explained (see Nature 389, 47-49; 1997).

Around 50 foreign scientists have been invited to the meeting, one of several events planned by IIAP to mark the centenary. But some institute scientists are concerned about the potential impact of the renovation work on the historic observatory.

The roof of the main hall, the heart of the observatory connecting the two domes (pic-

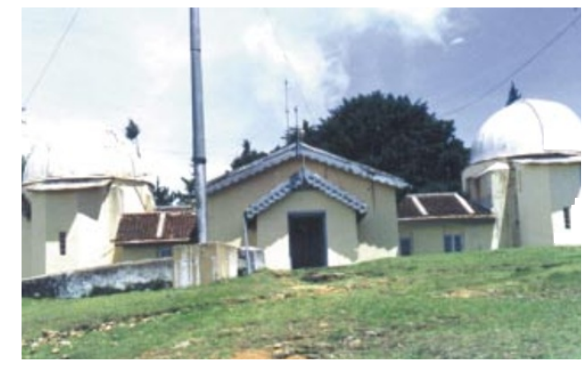

Kodaikanal observatory: preparing to host an international meeting to mark its centenary.

tured above), has already been dismantled to make way for the auditorium. According to one scientist, a stone pier that supported the man-sized Shelton astronomical clock has been thrown away and the clock has been put in another building.

The Kodaikanal observatory was set up in British-ruled India by meteorologists, not physicists. According to Rajesh Kochhar, an IIAP astronomer and a science historian, this followed "a famine in the Madras presidency which underscored the need for a study of the Sun so that monsoon patterns could be better understood".

According to Kochhar, throughout its 100 years of existence, the Kodaikanal observatory has been an important international research facility, cooperating with observatories in Paris, Greenwich, Mount Wilson and Cambridge.

IIAP director Ramnath Cowsik denies any "damage to the building or the instruments". He says that the renovation work is being carried out in accordance with the suggestions of the Archaeological Survey of India, and that any displaced instruments have been preserved in another laboratory along with the Shelton clock.

IIAP is fully funded and owned by the central government through the Department of Science and Technology. Valangiman Ramamurthi, the department's secretary, says that damage to the observatory is being exaggerated. He adds that the department is prepared to have the renovation work examined by a team from the Indian National Trust for Arts and Cultural Heritage, the body responsible for the preservation of historic sites.

K.S.Jayaraman

\section{Animal rights activists attack Gore over chemical screening}

[WASHINGTON] Animal rights activists launched a series of television advertisements last week attacking US Vice-President Al Gore for backing a controversial government programme to screen common chemicals for toxicity.

People for the Ethical Treatment of Animals (PETA) is running the advertisements in New Hampshire and Iowa, which are key political states for Gore, a presidential hopeful. In the advertisements, television actress Bea Arthur says that Gore wants to poison and kill millions of animals "just to prove things like turpentine and rat poison are dangerous".

The six-year, \$500-700 million programme was launched by Gore in 1998 and is being run by the Environmental Protection Agency (EPA). It asks companies to screen 'voluntarily' 2,800 chemicals that are made or imported in quantities of more than a million pounds a year.

The list includes a wide array of substances, from caffeine to carbon tetrachloride. So far, 218 companies have signed up to screen 1,153 chemicals. In December, the EPA will begin requiring the participation of companies that have not volunteered. The data generated will be posted publicly on the Internet.

Seventeen animal rights groups, including the Humane Society, have written to Gore arguing that many of the chemicals "clearly need no further testing".

606
Other sceptics included the late congressman George Brown (Democrat, California). He wrote to Carol Browner, the EPA administrator, last December, citing concerns about "the welfare of millions of animals to be used in the testing" and that ample data already exist for many of the chemicals.

The critics argue that Gore and the EPA, by using high production volume as a surrogate marker for human and environmental exposure, are needlessly targeting chemicals that are either benign, or toxic but already well characterized.

Procter \& Gamble, which is participating in the programme, wrote to Browner in January saying: "We are concerned that EPA will be perceived as 'setting back the clock' by failing to apply thoughtful scientific approaches" to reducing the use of animals.

Katherine Stitzel, associate director of the company's human safety department, argues that the agency is "just looking at whether the material is toxic at the largest dose possible to an animal. We don't think that is germane to exposure to the environment and humans."

Others in industry support the programme's use of animals, including the Chemical Manufacturers Association. The association's spokesman Tom Gilroy says: “Companies don't want to do any more [animal] testing than is necessary. It is expensive. But they want their data to be of sufficient quality that it's accepted."

Gore, environmentalists and the EPA argue that there is a dearth of publicly available information about the chemicals, and that some animal sacrifice is justified in the pursuit of public health and environmental protection.

The EPA says that full screening data, defined by the Organization for Economic Cooperation and Development, are available for only seven per cent of the 2,800 chemicals.

"The bottom line goal is to protect children and adults from being exposed to chemicals that may be harmful," says Chris Lehane, Gore's press secretary.

William Sanders, director of the EPA's Office of Pollution Prevention and Toxics, estimates that "a fraction of a million" animals, mostly rats, will be killed under the programme.The EPA initially estimated that up to two million animals would die. But it later revised its recommendations on how companies should test, proposing the use of some non-animal alternatives, and that tests on chemicals of similar structure should be consolidated.

Alan Goldberg, director of the Johns Hopkins Center for Alternatives to Animal Testing, says the EPA has been "remarkably responsive in trying to follow a humane approach". But animal activists argue that the agency cannot require companies to minimize the use of animals because the programme is voluntary. Meredith Wadman 